\title{
Mixed-phase MOF-derived Titanium Dioxide for Photocatalytic Hydrogen Evolution: The Impact of the Templated Morphology
}

\author{
Stavroula Kampouri[ ${ }^{[\mathrm{a}] \dagger}$, Christopher P. Ireland ${ }^{[\mathrm{a}] \dagger}$, Bardiya Valizadeh ${ }^{[\mathrm{a}]}$, Emad Oveisi $^{[\mathrm{b}]}$, Pascal A. Schouwink ${ }^{[\mathrm{c}]}$, \\ Mounir Mensi $^{[\mathrm{c}]}$ and Kyriakos C. Stylianou ${ }^{[\mathrm{a}]^{*}}$ \\ [a] Laboratory of Molecular Simulation (LMSO), Institute of Chemical Sciences and Engineering, École Polytechnique \\ Fédérale de Lausanne (EPFL Valais), Rue de l'industrie 17, 1951 Sion, Switzerland, \\ [b] Interdisciplinary Center for Electron Microscopy, École Polytechnique Fédérale de Lausanne (EPFL), CH-1015 \\ Lausanne, Switzerland, \\ [c] Institute of Chemical Sciences and Engineering, École Polytechnique Fédérale de Lausanne (EPFL Valais), Rue de \\ l'industrie 17, 1951 Sion, Switzerland
}

\begin{abstract}
:
Herein, we explored a simple metal-organic framework (MOF) mediated synthesis for the controlled preparation of pure and mixed phase titania $\left(\mathrm{TiO}_{2}\right)$ nanoparticles. Scanning electron microscopy images revealed that the MOF-derived $\mathrm{TiO}_{2}$ retain the MOF crystal shape, and through powder X-ray diffraction and X-ray photoelectron spectroscopy, it is demonstrated that the crystal-template is composed of nanosized $\mathrm{TiO}_{2}$ rutile and anatase particles. The presence of both $\mathrm{TiO}_{2}$ rutile and anatase phases in the crystal-template enhances the interactions between them, thus suppressing the electron-hole recombination. This has an impact toward the photocatalytic reduction of water as the templated MOF-derived $\mathrm{TiO}_{2}$ outperforms the commercial (P25 Degussa), titanium isopropoxide-derived and non-templated MOF-derived $\mathrm{TiO}_{2}$. Our study demonstrates that the morphologicallyinduced high charge separation efficiency afforded by using MOF crystals as precursors can lead to the generation of catalytically more active materials that can challenge existing photocatalysts in the field of hydrogen generation.
\end{abstract}

KEYWORDS: photocatalysis, hydrogen evolution, $\mathrm{MIL}-125-\mathrm{NH}_{2}$, TiO2, templated morphology, MOFmediated synthesis

\section{INTRODUCTION}

The atmospheric pollution induced by the combustion of fossil fuels, along with the continuously growing energy demand have prompted intense research in the employment of hydrogen $\left(\mathrm{H}_{2}\right)$, as an environmentally friendly energy carrier. Among other ways, such as steam methane reformation or coil gasification, photocatalytic water splitting is a sustainable approach to produce $\mathrm{H}_{2}$ by harnessing light energy, which can be provided by the inexhaustible sun. ${ }^{1}$ Titanium dioxide $\left(\mathrm{TiO}_{2}\right)$ was the first material investigated for the photocatalytic splitting of water ${ }^{2-4}$ and is still considered among the most promising photocatalysts, due to its chemical and thermal stability, non-toxicity, high reactivity and low cost. ${ }^{5-7}$ Despite the fact that tremendous research efforts have been focused on the use of $\mathrm{TiO}_{2}$ nanoparticles (NPs) in a variety of photocatalytic applications (water splitting, water remediation, $\mathrm{CO}_{2}$ reduction), ${ }^{8}$ the impact of the shape and morphology of $\mathrm{TiO}_{2} \mathrm{NPs}$ as well as the interplay between the two most common phases of $\mathrm{TiO}_{2}$ (rutile and anatase) remain questionable. 
The low temperature $\mathrm{TiO}_{2}$ anatase phase is generally recognized as a better catalyst towards the $\mathrm{H}_{2}$ evolution reaction, due to the surface hydration, meaning that a higher concentration of active sites is present compared with the $\mathrm{TiO}_{2}$ rutile phase. Nevertheless, the more thermodynamically stable $\mathrm{TiO}_{2}$ rutile phase has a smaller band gap implying that a significant higher proportion of light can be absorbed, thus careful engineering of a single $\mathrm{TiO}_{2}$ rutile phase particles can lead to enhanced photocatalytic performance. ${ }^{9}$ On the other hand, materials based on mixed $\mathrm{TiO}_{2}$ rutile and anatase phases have demonstrated superior photocatalytic performance in comparison with the single phase $\mathrm{TiO}_{2}{ }^{10-14} \mathrm{P} 25$ Degussa, a mixed phase commercial $\mathrm{TiO}_{2}$ is widely used as a standard material for photocatalysis and was studied by Bickley in 1990 to ascertain its success compared to a single phase $\mathrm{TiO}_{2}{ }^{10}$ The conclusion was that the excellent electronic contact between the two phases allowed successful electron-hole separation.

Subsequent literature has both agreed ${ }^{11-12}$ and disputed ${ }^{13}$ these findings and specifically the morphology of the phases' interface and the interactions between them. However, ample evidence has been provided through both experimental and computational approaches to prove that there is indeed a synergy between the anatase and rutile phases, allowing more efficient electron-hole separation. ${ }^{14} \mathrm{~A}$ general understanding has therefore been developed that $\mathrm{TiO}_{2}$ materials with the anatase and rutile phases in a 3:1 ratio can outperform comparably formed single phase $\mathrm{TiO}_{2}$. The different structural arrangement of $\mathrm{TiO}_{2}$ anatase and rutile phases affords distinct phase electronic structures. As conclusively demonstrated by Scanlon et al., ${ }^{15}$ close electronic contact between the two phases allows electrons on rutile $\mathrm{TiO}_{2}$ to irreversibly transfer to the complementary $\mathrm{TiO}_{2}$ anatase phase, with this synergy promoting the electron-hole separation.

In order to engineer this electronic contact between the two $\mathrm{TiO}_{2}$ phases, several synthetic techniques have been utilized; approaches of physically mixing anatase and rutile $\mathrm{TiO}_{2}$ have been attempted, but mixing does not allow the two phases to sufficiently interact with each other and achieve this synergy. ${ }^{16-17}$ Synthetic efforts on mixed phase $\mathrm{TiO}_{2}$ have employed the sol-gel route, hydro/solvo-thermal method, electrodeposition, direct oxidation method or chemical vapor deposition. ${ }^{18}$ Many of these techniques, however lack of control, are impractical or may not provide highly active and stable $\mathrm{TiO}_{2} \mathrm{NPs}$.

Metal-organic frameworks (MOFs) are crystalline materials that consist of metal ions or clusters coordinated to organic ligands to form 3-dimensional porous structures. Due to their high crystallinity, structural tuneability and porous nature, MOFs have been extensively explored for a variety of applications. ${ }^{19-20}$ Whilst, MOFs themselves have high potential, limitations related to their thermal and chemical stability have recently triggered their utilization as precursors for the preparation of highly stable metal oxides with catalytic activities. ${ }^{21-26}$ More specifically, the MOF-mediated synthesis involves the use of MOFs as crystalline self-sacrificing templates in order to tailor the shape, composition, surface area and stability of the resulting materials. ${ }^{27-28}$ Calcination of MOFs in air leads to the partial or complete burning of the organic ligands and formation of highly active metaloxide NPs, while carbonization at high temperature under inert conditions can result in a carbon matrix encapsulating the metal phase (NPs) and thus avoiding sintering effects. ${ }^{29}$

Among the $\mathrm{Ti}^{\mathrm{IV}}$-based MOFs, the MIL-125 series consisting of functionalized (or not) ligands exhibit a 3dimensional and porous structure, and represent the most studied $\mathrm{Ti}^{\mathrm{IV}}$-based $\mathrm{MOFs}$ for photocatalytic applications. ${ }^{30-32}$ Recently, MIL-125- $\mathrm{NH}_{2}$ was utilized as a precursor for the synthesis $\mathrm{TiO}_{2}$ particles, decorated with either palladium or gold NPs for photocatalytic applications, such as $\mathrm{CO}_{2}$ reduction and hydrogen evolution. ${ }^{33-34}$ The employment of expensive noble metal NPs as co-catalysts was necessary to enhance the 
otherwise inadequate photocatalytic performance of $\mathrm{TiO}_{2}$, due to high electron-hole recombination rates. Although these studies provided important insights, there is still a need to better understand the impact of templated MOF-derived $\mathrm{TiO}_{2}$ rutile and anatase phases, and the effect of the morphology on the synergy between the two phases in photocatalysis.

Herein, we investigate primarily the photocatalytic performance of $\mathrm{TiO}_{2}$ prepared using the MIL-125- $\mathrm{NH}_{2}$ as a starting material. By calcining MIL-125- $\mathrm{NH}_{2}$ over a range of temperatures, the ratio of the anatase and rutile phases could be controlled. The resulting $\mathrm{TiO}_{2}$ retained the well-defined crystal shape of the parent MOF upon heating. The best performing mixed $\mathrm{TiO}_{2}$ anatase-rutile phase (ratio 66:34) exhibits a $\mathrm{H}_{2}$ evolution rate of 1394 $\mu$ mol $\mathrm{h}^{-1} \mathrm{~g}^{-1}$. For comparison, MIL-167-derived $\mathrm{TiO}_{2}$, and $\mathrm{TiO}_{2}$ synthesized from precipitated amorphous titanium hydroxide were prepared, all of which demonstrated inferior photocatalytic performances. Morphological studies revealed the unique nature of the templated MIL-125- $\mathrm{NH}_{2}$-derived $\mathrm{TiO}_{2}$ with nanosized anatase and rutile NPs forced into effective contact with each other, leading to an efficient electron-hole separation. In addition, the templated MIL-125- $\mathrm{NH}_{2}$-derived mixed phase $\mathrm{TiO}_{2}$ outperforms the commercial Degussa $\mathrm{P} 25 \mathrm{TiO}_{2}$. Our work highlights the role of effective interactions of $\mathrm{TiO}_{2}$ anatase and rutile phases in a template, and offers an intriguing outline for the development of efficient photocatalysts.

\section{RESULTS AND DISCUSSION}

MIL-125- $\mathrm{NH}_{2}$ was synthesized based on a reported procedure (see section $\left.\mathrm{S} 1.2\right)^{35}$ and its phase purity was confirmed by powder X-ray diffraction (PXRD) (Figure S1). Prior to the MOF-mediated synthesis of $\mathrm{TiO}_{2}$, the thermogravimetric analysis (TGA) of MIL-125- $\mathrm{NH}_{2}$ was carried out. Figure 1a shows the TGA profile of MIL125- $\mathrm{NH}_{2}$. Two major weight losses are observed; from 30 to $\sim 200{ }^{\circ} \mathrm{C}$, owed to the removal of guest molecules from the pores of the MIL-125- $\mathrm{NH}_{2}$ and from 360 to $600{ }^{\circ} \mathrm{C}$ related to the structural collapse of MIL-125- $\mathrm{NH}_{2}$. The final product obtained after heating MIL-125- $\mathrm{NH}_{2}$ at $600{ }^{\circ} \mathrm{C}$ corresponds to the remaining metal oxide, $\mathrm{TiO}_{2}$, as confirmed by PXRD.

Acquiring a clear perception regarding the thermally-induced structural collapse of the MIL-125- $\mathrm{NH}_{2}$, allowed us to continue with the synthesis of MOF-derived $\mathrm{TiO}_{2}$ at selected temperatures $\left(400-800{ }^{\circ} \mathrm{C}\right.$ ) under air (see section $\mathrm{S} 1.2$, Figure 1b). As can be seen in Figure 1c, calcination at different temperatures yields $\mathrm{TiO}_{2}$ with differing ratios of the $\mathrm{TiO}_{2}$ anatase and rutile phases. The anatase to rutile transformation is reconstructive, meaning that it involves the breaking of chemical bonds. The transformation temperature itself can vary depending on the starting material particle size, shape and volume and experimental factors such as atmosphere, heating rate and sample container. Reported temperatures for the $\mathrm{TiO}_{2}$ anatase to rutile transformation vary from 400 to $1200^{\circ} \mathrm{C} \cdot{ }^{36}$

Presently, heating the MIL-125- $\mathrm{NH}_{2}$ crystals up to $400{ }^{\circ} \mathrm{C}$ leads to the formation of pure $\mathrm{TiO}_{2}$ anatase phase. Increasing the temperature to $500^{\circ} \mathrm{C}$ induces the formation of the rutile phase (giving rise to a mixed phase $\mathrm{TiO}_{2}$ ), which gradually becomes the dominant phase at $800{ }^{\circ} \mathrm{C}$. Here, the anatase to rutile phase transformation is at the lower end of the temperature range reported for this transformation..$^{37} 38$

Further insights into the specific crystallization process can be gained from a variable temperature (VT) PXRD experiment, where MIL-125- $\mathrm{NH}_{2}$ enclosed in a quartz capillary was heated from 30 to $800{ }^{\circ} \mathrm{C}$ (see section $\mathrm{S} 1.3$, Figure S2, Figure S3). Although direct comparison of ex-situ and in-situ experiments is not applicable (due to the crystallization process being rather complex and related to heating rate, dwell time and volume of the heating 
vessel), the in-situ VT PXRD experiment offers an insight into the $\mathrm{TiO}_{2}$ anatase and rutile phase formation. Upon heating, the PXRD patterns show that the Bragg reflections of MIL-125- $\mathrm{NH}_{2}$ are eliminated due to decomposition, leading to an amorphous powder. Upon further heating, initial formation of the $\mathrm{TiO}_{2}$ anatase phase is observed as a broad hump at $25.2^{\circ} 2 \theta$ (Figure S2), at furnace temperature of $560{ }^{\circ} \mathrm{C}$. The peak width (Full width half maximum: FWHM 1.7320 ) manifests a lack of crystallinity which can be indicative of defects and a small domain size. This poor crystallinity may be related to the removal of the organic ligand which disrupts the crystallization process at the initial stages of $\mathrm{TiO}_{2}$ formation. Interestingly, further heating to $660^{\circ} \mathrm{C}$ revealed the formation of a more crystalline $\mathrm{TiO}_{2}$ rutile phase with a FWHM of $0.312 \theta$. The integral intensity of the $\mathrm{TiO}_{2}$ anatase Bragg peak remains constant during initial rutile formation, suggesting that the initial formation results from the same matrix as anatase. Both phases co-exist before the $\mathrm{TiO}_{2}$ rutile phase becomes the dominant phase at $785{ }^{\circ} \mathrm{C}$. The $\mathrm{TiO}_{2}$ anatase and rutile phase composition, and the average domain size were quantified by Rietveld refinement from the as-prepared $\mathrm{TiO}_{2}$ samples (Table 1). It is found that the domain size for both $\mathrm{TiO}_{2}$ anatase and rutile phases is comparable at the same temperature, and increases with temperature.

To serve as a reference, different pure and mixed phase $\mathrm{TiO}_{2}$ were also obtained by calcining $\left(400-800{ }^{\circ} \mathrm{C}\right)$ precipitated amorphous titanium hydroxide $\left(\mathrm{TiH}_{4} \mathrm{O}_{4}\right)$ as a starting material (see section S1.2). The TGA profile of the $\mathrm{TiH}_{4} \mathrm{O}_{4}$ shows a weight loss up to $450{ }^{\circ} \mathrm{C}$, related to the removal of hydroxide, coordinated water and/or organic residues derived from the titanium isopropoxide (Figure S4). Upon calcination, the $\mathrm{TiO}_{2}$ anatase to rutile phase transformation starts at $700{ }^{\circ} \mathrm{C}$ and above this temperature, the $\mathrm{TiO}_{2}$ rutile phase becomes dominant (Figure 1d). VT PXRD experiments collected on $\mathrm{TiH}_{4} \mathrm{O}_{4}$, using the same protocol used with MIL-125- $\mathrm{NH}_{2}$ revealed that the formation of $\mathrm{TiO}_{2}$ anatase phase begins at a significantly lower temperature than the MIL-125$\mathrm{NH}_{2}$-derived $\mathrm{TiO}_{2}$, with peaks of anatase identified as low as $180^{\circ} \mathrm{C}$ (Figure S5, Figure S6). Interestingly, the qualitative trend of domain-sizes of anatase and rutile is inversed between MIL-125- $\mathrm{NH}_{2}$ and $\mathrm{TiH}_{4} \mathrm{O}_{4}$-derived samples, with initial rutile formation from $\mathrm{TiH}_{4} \mathrm{O}_{4}$ showing a much larger FWHM than from MIL-125-NH2 . This suggests that nucleation and growth proceeds through different mechanisms, which is likely related to the topological differences between a pre-existing framework/matrix of Ti-O polyhedral in $\mathrm{TiH}_{4} \mathrm{O}_{4}$ as opposed to discrete Ti-O clusters separated by the organic ligands in MIL-125- $\mathrm{NH}_{2}$. Furthermore, the ex-situ determined domain size of the $\mathrm{TiO}_{2}$ anatase phase is significantly greater than that of the MIL-125- $\mathrm{NH}_{2}$-derived material, with the FWHM only 0.7320 , implying a much higher degree of crystallinity. This improved crystallinity delays the formation of the rutile phase to $710^{\circ} \mathrm{C} .{ }^{36}$

X-ray photoelectron spectroscopy (XPS) were performed, to analyze the surface of the mixed phase material. XPS revealed a titanium $2 p$ peak at a binding energy of $458.5 \mathrm{eV}$. Each $\mathrm{TiO}_{2}$ rutile and anatase phase has a distinct binding energy separated by $0.4 \mathrm{eV}$, allowing us to quantify the composition of both phases on the surface of $\mathrm{TiO}_{2} \cdot{ }^{15}$ From the fitting, the $\mathrm{TiO}_{2}$ anatase and rutile phase composition of the MIL-125-NH2-derived $\mathrm{TiO}_{2}$ at $600{ }^{\circ} \mathrm{C}$ is $15: 85$ (Figure $\mathrm{S} 7 \mathrm{a}$ ) indicating a higher rutile content on the surface compared to the bulk (66:34). This higher surface rutile content is also the case with the $\mathrm{TiH}_{4} \mathrm{O}_{4}$-derived $\mathrm{TiO}_{2}$ (Figure S7b). This analysis is consistent with the thermal heating process involved, whereby the surface of the particle is where the initial transformation between anatase and rutile takes place. 


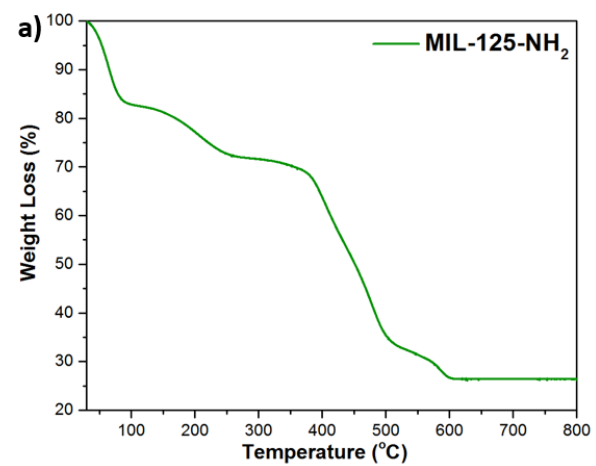

b)
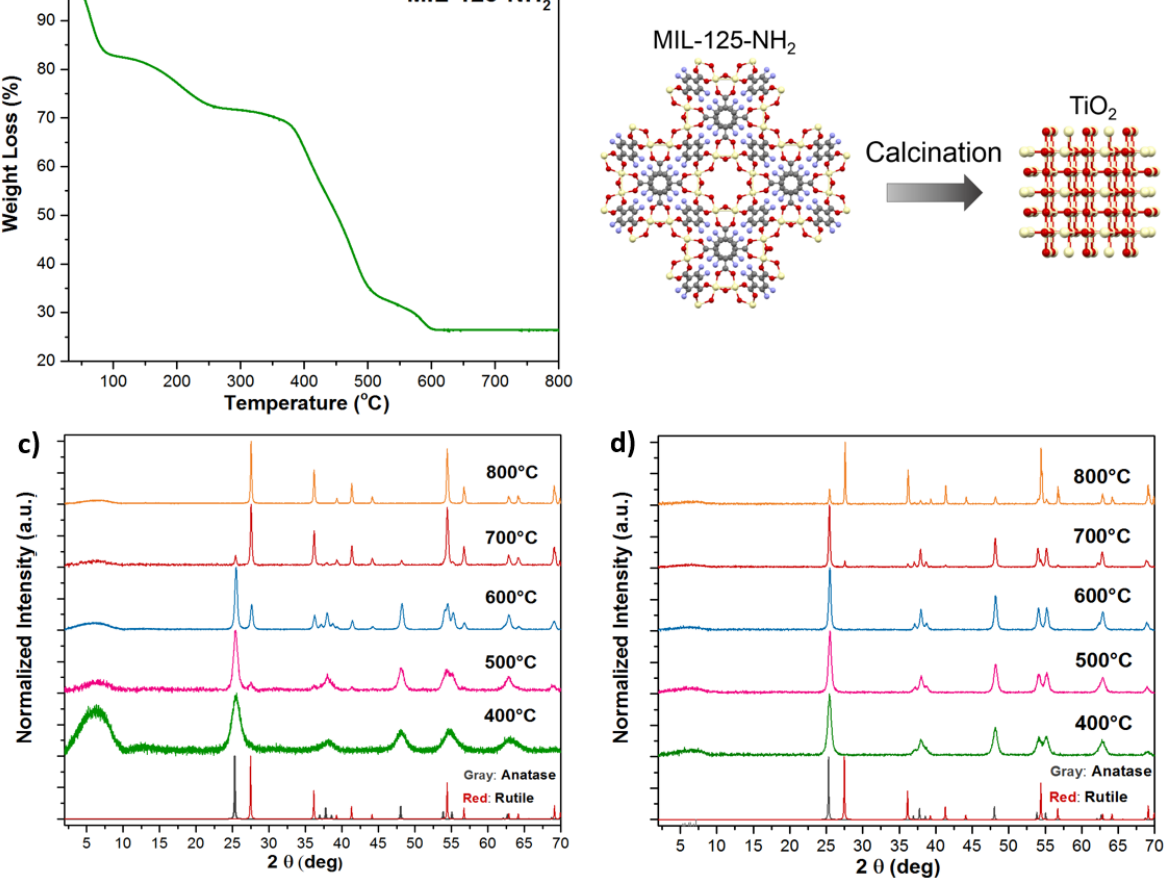

Figure 1. a) TGA curve of MIL-125- $\mathrm{NH}_{2}$ obtained under airflow with a heating rate of $5{ }^{\circ} \mathrm{C} \min ^{-1}$. b) Schematic illustration of the synthetic procedure of MIL-125- $\mathrm{NH}_{2}$-derived $\mathrm{TiO}_{2}$. PXRD patterns of the as-synthesized c) MIL-125- $\mathrm{NH}_{2}$-derived and d) $\mathrm{TiH}_{4} \mathrm{O}_{4}$-derived $\mathrm{TiO}_{2}$.

Figure S8 displays the Kubelka-Munk representation of the UV-vis diffuse reflectance spectra of $\mathrm{TiO}_{2}$ synthesized from MIL-125- $\mathrm{NH}_{2}$ and $\mathrm{TiH}_{4} \mathrm{O}_{4}$. The spectra of both families are in agreement with the literature, ${ }^{39}$ with the presence of rutile, which has a smaller band gap, causing a red shift in the light absorption edge compared to phase pure anatase $\mathrm{TiO}_{2}$. In the case of the MIL-125- $\mathrm{NH}_{2}$-derived $\mathrm{TiO}_{2}$ synthesized through calcination at $400{ }^{\circ} \mathrm{C}$, there is an extended light absorbance in the visible region, which is attributed to the residual carbon from the MIL-125- $\mathrm{NH}_{2}$ covering the surface of $\mathrm{TiO}_{2}$ and is in agreement with the TGA data (Figure 1a).

Table 1. PXRD-derived data revealing the size and composition of $\mathrm{TiO}_{2}$ synthesized using MIL-125- $\mathrm{NH}_{2}$ and $\mathrm{TiH}_{4} \mathrm{O}_{4}$ as precursors.

\begin{tabular}{|c|c|c|c|c|c|c|c|c|c|c|}
\hline & \multicolumn{5}{|c|}{ MIL-125-NH2-derived $\mathrm{TiO}_{2}$} & \multicolumn{5}{|c|}{$\mathrm{TiH}_{4} \mathrm{O}_{4}$-derived $\mathrm{TiO}_{2}$} \\
\hline Synthesis Temp. $\left({ }^{\circ} \mathrm{C}\right)$ & 400 & 500 & 600 & 700 & 800 & 400 & 500 & 600 & 700 & 800 \\
\hline Anatase (w.t. \%) & 98 & 87 & 66 & 11 & - & 100 & 100 & 100 & 92 & 20 \\
\hline Rutile (w.t. \%) & 2 & 13 & 34 & 89 & 100 & - & - & - & 8 & 80 \\
\hline Size Anatase (nm) & 5.7 & 11 & 22 & 44 & - & 13 & 17 & 26 & 43 & 56 \\
\hline Size Rutile (nm) & 5.9 & 12 & 25 & 47 & 61 & - & - & - & 87 & 87 \\
\hline
\end{tabular}

The morphologies of MIL-125- $\mathrm{NH}_{2}$ - and $\mathrm{TiH}_{4} \mathrm{O}_{4}$-derived $\mathrm{TiO}_{2}$ were investigated through scanning electron microscopy (SEM) (see section S2.7). As can be seen in Figure 2, the well-defined crystal shape of MIL-125- 
$\mathrm{NH}_{2}$ is retained during heating. It is found that the $\mathrm{MIL}-125-\mathrm{NH}_{2}$-derived $\mathrm{TiO}_{2}$ exhibits a rectangular parallelepiped with round corners shape and its size is significantly reduced compared to the $1 \mu \mathrm{m}$ MIL-125$\mathrm{NH}_{2}$-crystals (Figure 2a). The size reduction is associated with the high calcination temperature and subsequently to the removal of the guest-molecules and organic ligand in MIL-125- $\mathrm{NH}_{2}$. Transmission electron microscopy (TEM) images show that the crystal-templates consisted of nanosized $\mathrm{TiO}_{2} \mathrm{NPs}$ (Figure $3 \mathrm{a}, \mathrm{b}, \mathrm{S} 9$ and S10). This is further confirmed by dark-field TEM, where the incident electron beam is tilted so that only the reflections of specific diffracting crystallographic planes contribute to image formation (Figure S9 and S10). Depending on the diffraction angle, $\mathrm{TiO}_{2} \mathrm{NPs}$ of specific crystallographic orientation are illuminated in the darkfield image, confirming the multi-particle nature of the crystal-template. The co-existence of both $\mathrm{TiO}_{2}$ rutile and anatase phases produced at $600{ }^{\circ} \mathrm{C}$ was additionally proven by selected area electron diffraction (SAED) pattern measurements (Figure 3c). The observed diffraction pattern is comparable with Bikley's seminal work on P25, with the many nanosized $\mathrm{TiO}_{2}$ particles diffracting to give Debye-Scherrer rings. ${ }^{10}$ These rings can be indexed to both $\mathrm{TiO}_{2}$ anatase and rutile phases, confirming the multiphase nature of this material (Figure $3 \mathrm{c}$ ).

In contrast to the MIL-125- $\mathrm{NH}_{2}$-derived $\mathrm{TiO}_{2}$, the morphology of $\mathrm{TiH}_{4} \mathrm{O}_{4}$-derived $\mathrm{TiO}_{2}$ resembles disordered arrangement of bulk aggregates (Figure S11, S12 and S13), typical of precipitated and co-precipitated metal

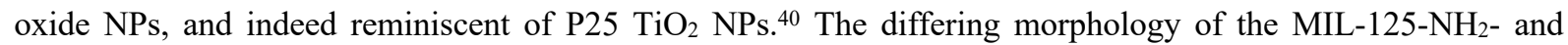
$\mathrm{TiH}_{4} \mathrm{O}_{4}$-derived $\mathrm{TiO}_{2}$ offer up an intriguing question of how this could affect the synergy between the $\mathrm{TiO}_{2}$ anatase and rutile phases.

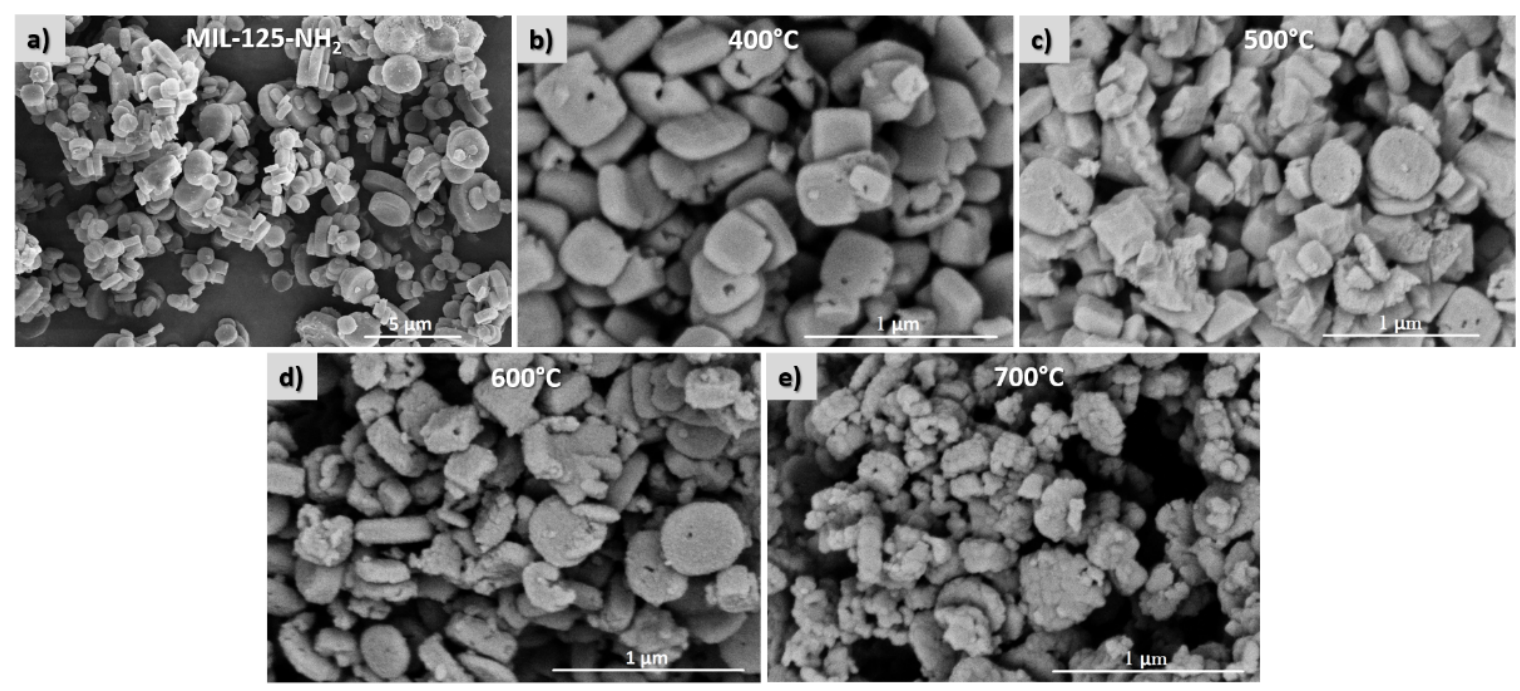

Figure 2. SEM image of a) MIL-125- $\mathrm{NH}_{2}$ and MIL-125- $\mathrm{NH}_{2}$-derived $\mathrm{TiO}_{2}$ samples synthesized at b) $400{ }^{\circ} \mathrm{C}$, c) $500{ }^{\circ} \mathrm{C}$, d) $600{ }^{\circ} \mathrm{C}$ and e) $700{ }^{\circ} \mathrm{C}$ for $1 \mathrm{~h}$. The images are of the same magnification except for MIL-125- $\mathrm{NH}_{2}$, which is of 5 times less magnification in order to display the morphology of the larger MOF crystals. 

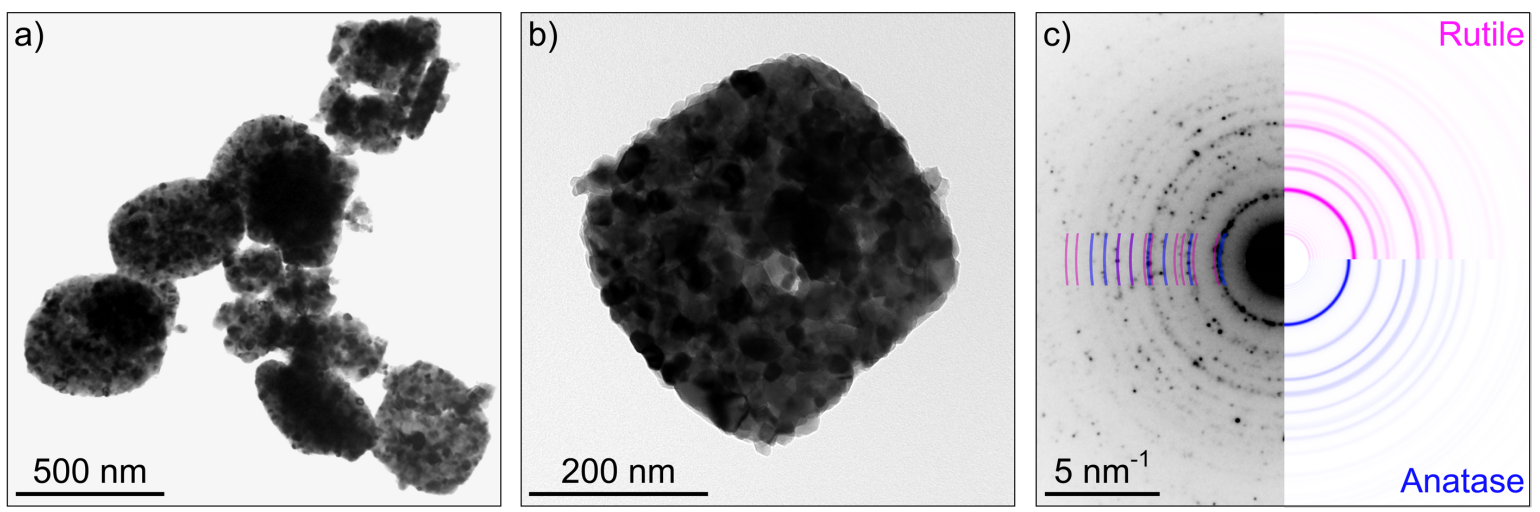

Figure 3. a,b) Bright-field TEM images and c) selected area electron diffraction pattern of MIL-125- $\mathrm{NH}_{2}$-derived $\mathrm{TiO}_{2}$ synthesized through calcination at $600^{\circ} \mathrm{C}$ for $1 \mathrm{~h}$. Simulated electron diffraction patterns of anatase and rutile phases (ring sampling diffraction planes) are shown to the right of the image for reference.

After characterization, the performance of the MIL-125- $\mathrm{NH}_{2}$-derived $\mathrm{TiO}_{2} \mathrm{NPs}$ was investigated toward the photocatalytic $\mathrm{H}_{2}$ evolution from water, with methanol used as the sacrificial electron donor $(20 \mathrm{v} / \mathrm{v} \%)$ in the absence of co-catalyst, under UV-Vis light radiation, from a $300 \mathrm{~W}$ Xe lamp (see section S3). As shown in Figure $4 \mathrm{a}$, the ratio between the $\mathrm{TiO}_{2}$ anatase and rutile phases was found to have a profound impact on the photocatalytic performance. More specifically, increasing the rutile phases induces a volcano type trend with respect to the $\mathrm{H}_{2}$ evolution rate. The sample with a composition of 66 w.t. $\% \mathrm{TiO}_{2}$ anatase and 34 w.t.\% $\mathrm{TiO}_{2}$ rutile (synthesized through calcination of MIL-125- $\mathrm{NH}_{2}$ at $600^{\circ} \mathrm{C}$ ) exhibits the highest $\mathrm{H}_{2}$ evolution rate of 1394 $\mu \mathrm{mol} \mathrm{h}{ }^{-1} \mathrm{~g}^{-1}$. Materials with higher amounts of $\mathrm{TiO}_{2}$ rutile phase deteriorate their photocatalytic performance and the $\mathrm{H}_{2}$ evolution rate for the $\mathrm{TiO}_{2}$ with composition of 11 w.t. $\% \mathrm{TiO}_{2}$ anatase, 89 w.t. $\% \mathrm{TiO}_{2}$ rutile is $372 \mu \mathrm{mol}$ $\mathrm{h}^{-1} \mathrm{~g}^{-1}$. The same trend between the activity and the ratio between the $\mathrm{TiO}_{2}$ anatase and rutile phases was observed for the $\mathrm{TiH}_{4} \mathrm{O}_{4}$-derived $\mathrm{TiO}_{2}$, with the 92 w.t $\%$ anatase and 8 w.t. $\%$ rutile $\mathrm{TiO}_{2}$ exhibiting the best photocatalytic performance, with a $\mathrm{H}_{2}$ evolution rate of $259 \mu \mathrm{mol} \mathrm{h}^{-1} \mathrm{~g}^{-1}$ (Figure $4 \mathrm{~b}$ ).

The higher photoactivity of the mixed-phase $\mathrm{TiO}_{2}$ ( 66 w.t.\% $\mathrm{TiO}_{2}$ anatase and 34 w.t.\% $\mathrm{TiO}_{2}$ rutile), as compared to the phase pure $\mathrm{TiO}_{2}$ anatase or rutile, is thought to be owed to the synergistic effect between the two polymorphs. This allows for a more efficient charge carrier separation, provided that the two phases are in good electronic contact. The photogenerated electrons flow from the $\mathrm{TiO}_{2}$ rutile to the $\mathrm{TiO}_{2}$ anatase phase, which finally catalyzes the $\mathrm{H}_{2}$ evolution reaction. ${ }^{15}$ Recycling experiments were carried out for the best performing $\mathrm{TiO}_{2}$ for three consecutive cycles. The photostability and the morphology of the MIL-125- $\mathrm{NH}_{2}$-derived $\mathrm{TiO}_{2}$ were fully preserved, with consistent $\mathrm{H}_{2}$ rates produced over 3 cycles (Figure S14a). The SEM images of $\mathrm{TiO}_{2}$ after photocatalysis demonstrated that the templated morphology of the material was conserved, and PXRD showed no loss of crystallinity with the same $\mathrm{TiO}_{2}$ anatase-rutile phase composition (Figure $\mathrm{S} 14 \mathrm{~b}$ and c). 

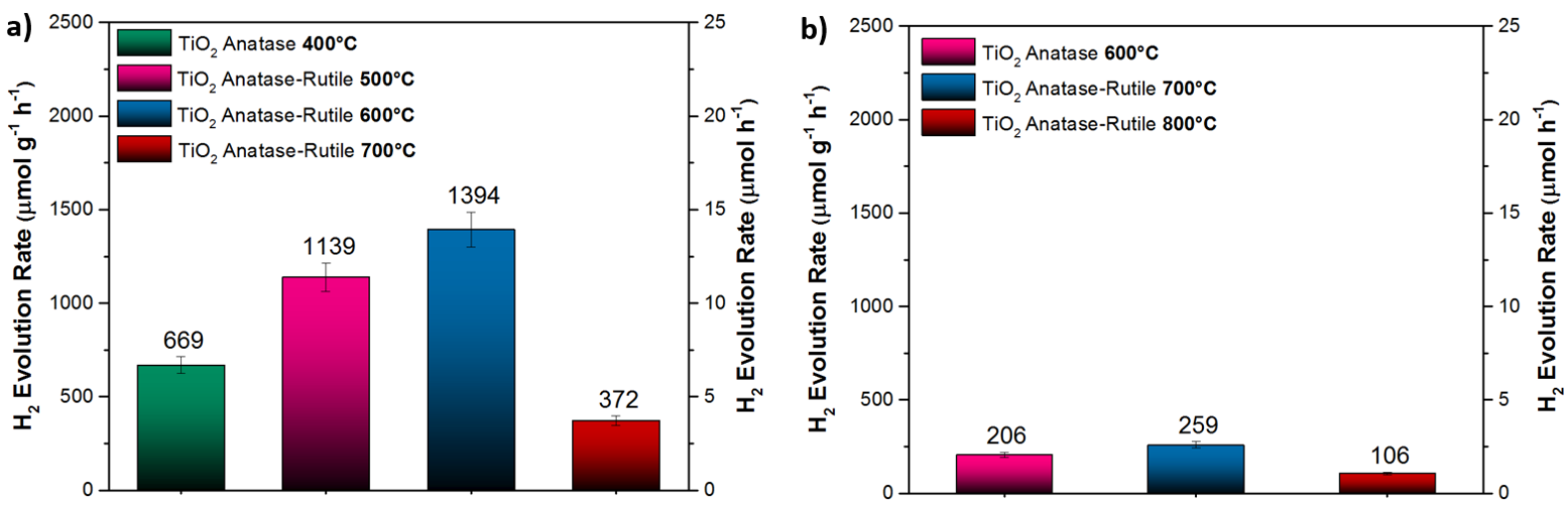

Figure 4. Comparison of $\mathrm{H}_{2}$ evolution rates of a) $\mathrm{MIL}-125-\mathrm{NH}_{2}$-derived $\mathrm{TiO}_{2}$ samples synthesized at different temperatures and b) $\mathrm{TiH}_{4} \mathrm{O}_{4}$-derived $\mathrm{TiO}_{2}$ samples synthesized at $600^{\circ} \mathrm{C}$ (anatase), $700^{\circ} \mathrm{C}$ (anatase-rutile) and $800^{\circ} \mathrm{C}$ (anatase-rutile).

Intrigued by these results, the photocatalytic performance of two additional $\mathrm{TiO}_{2}$ samples consisting of both the $\mathrm{TiO}_{2}$ anatase and rutile phases was explored; the commercial P25 Degussa $\mathrm{TiO}_{2}$ (with anatase-rutile phases in a composition of approximately $70: 30)^{40}$ and another MOF-derived $\mathrm{TiO}_{2}$ using MIL-167 as the precursor. ${ }^{41}$ Figure $\mathrm{S} 15$ demonstrates the successful synthesis of MIL-167-derived $\mathrm{TiO}_{2} \mathrm{NPs}$ by calcination of the precursor at $600{ }^{\circ} \mathrm{C}$ for $1 \mathrm{~h}$ in air (See section $\mathrm{S} 1.2$ ). Under these conditions, a mixed phase $\mathrm{TiO}_{2}$ with composition of $\mathrm{TiO}_{2}$ 75 w.t.\% anatase and 25 w.t.\% rutile was prepared (Table S1). SEM images (Figure S16) show that the morphology of MIL-167-derived $\mathrm{TiO}_{2}$ is based upon irregularly shaped aggregates with a large size of 5-20 $\mu \mathrm{m}$. Despite the use of crystalline MOF as precursor, the morphology of MIL-167-derived $\mathrm{TiO}_{2}$ is more comparable with the $\mathrm{TiH}_{4} \mathrm{O}_{4}$-derived $\mathrm{TiO}_{2}$ than the MIL-125- $\mathrm{NH}_{2}$ derived $\mathrm{TiO}_{2}$. TEM images indicate that the size of the MIL-167-derived $\mathrm{TiO}_{2} \mathrm{NPs}$ is $30-40 \mathrm{~nm}$, which is significantly larger than that of the $\mathrm{TiO}_{2} \mathrm{NPs}^{\mathrm{N}}$ derived from MIL-125- $\mathrm{NH}_{2}$ (Figure S17).

The photocatalytic performance of the different mixed phase $\mathrm{TiO}_{2}$ is shown in Figure 5a. The best MIL-125$\mathrm{NH}_{2}$-derived $\mathrm{TiO}_{2}$ outperforms all the other $\mathrm{TiO}_{2}$ samples, including the commercially available P25 Degussa. ${ }^{10}$ This is despite the relatively higher BET surface area of P25 Degussa compared to the other $\mathrm{TiO}_{2}$ samples (Figure S18). More specifically, the $\mathrm{P} 25$ Degussa $\mathrm{TiO}_{2}$ exhibited a $\mathrm{H}_{2}$ evolution rate of $624 \mu \mathrm{mol} \mathrm{h} \mathrm{h}^{-1} \mathrm{~g}^{-1}$, followed by the MIL-167-derived sample with a rate of $274 \mu \mathrm{mol} \mathrm{h}^{-1} \mathrm{~g}^{-1}$, which is comparable to that achieved by the $\mathrm{TiH}_{4} \mathrm{O}_{4}$-derived $\mathrm{TiO}_{2}\left(259 \mu \mathrm{mol} \mathrm{h}^{-1} \mathrm{~g}^{-1}\right)$. For the best performing MIL-125- $\mathrm{NH}_{2}$-derived $\mathrm{TiO}_{2}$ and $\mathrm{P} 25$ Degussa, the dependence of the $\mathrm{H}_{2}$ evolution rate on the concentration of photocatalyst in solution was further explored and found that the MIL-125- $\mathrm{NH}_{2}$-derived $\mathrm{TiO}_{2}$ reaches a higher plateau than that of the $\mathrm{P} 25$ Degussa $\mathrm{TiO}_{2}$ (Figure S19). This implies that the required amount of MIL-125- $\mathrm{NH}_{2}$-derived $\mathrm{TiO}_{2}$ photocatalyst is lower, indicative of a well dispersed sample in solution. ${ }^{42}$ The Kubelka-Munk representation of the UV-vis diffuse reflectance spectra of the examined samples is illustrated in Figure S20. The indirect band gap for each of the materials was extrapolated from the linear section of the Tauc plot for an indirect bandgap. It can be seen that the indirect band gap is similar for all samples; $2.96 \mathrm{eV}$ for MIL-125- $\mathrm{NH}_{2}$-derived and MIL-167-derived $\mathrm{TiO}_{2}, 2.98$ $\mathrm{eV}$ for $\mathrm{TiH}_{4} \mathrm{O}_{4}$-derived and $3.08 \mathrm{eV}$ for $\mathrm{P} 25$ Degussa. 

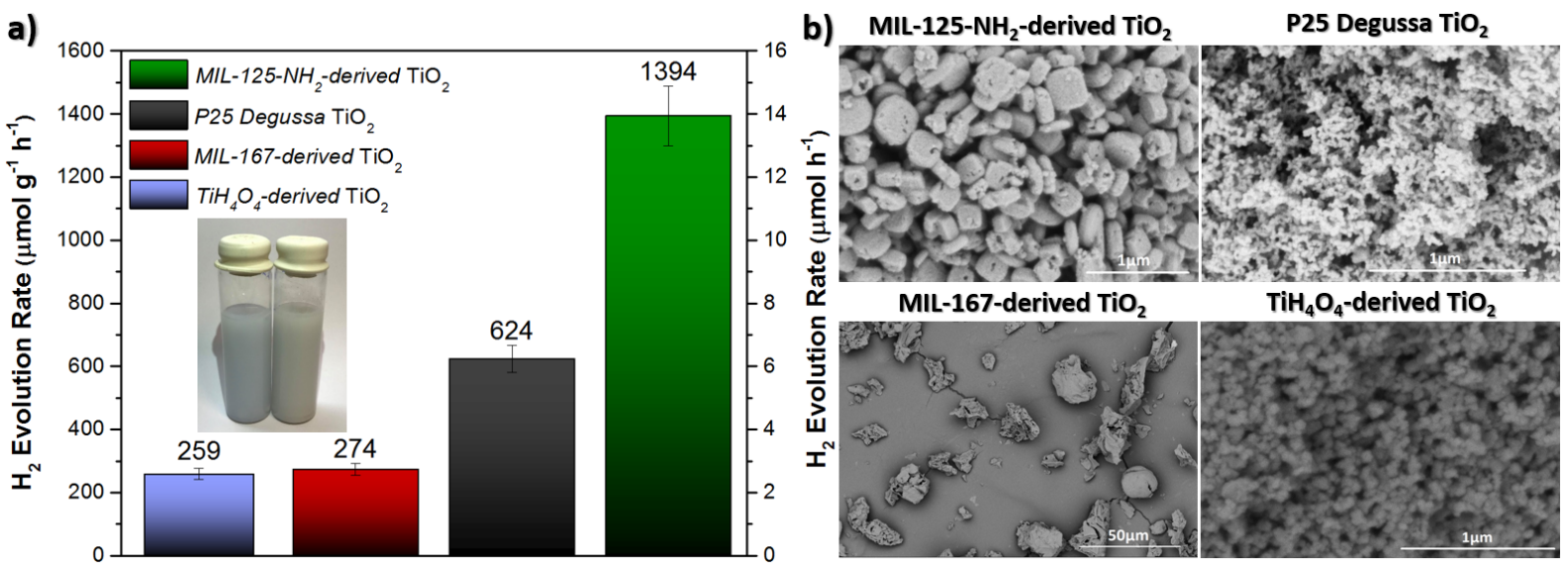

Figure 5. a) Comparison of photocatalytic activity and b) SEM images of the MIL-125- $\mathrm{NH}_{2}-$, MIL-167-, $\mathrm{TiH}_{4} \mathrm{O}_{4}$-derived $\mathrm{TiO}_{2}$ and P25 Degussa. Inset: Photograph of the light-blue-colored P25 Degussa (left) and the MIL-125- $\mathrm{NH}_{2}-\mathrm{derived}_{\mathrm{TiO}}$ (right), after the photocatalytic test.

The superior photocatalytic performance of the MIL-125- $\mathrm{NH}_{2}$-derived $\mathrm{TiO}_{2} \mathrm{NPs}$ over the other $\mathrm{TiO}_{2}$ samples can be attributed to the morphology differences observed in SEM and TEM images (Figure 5b). The fact that the precursors in MOF-mediated syntheses are themselves well-defined crystals allows the resulting templated $\mathrm{TiO}_{2}$ NPs to retain an exceptional close contact throughout the calcination and transformation process. These findings highlight that the $\mathrm{TiO}_{2}$ anatase to rutile phase ratio is not the only predominant factor determining the photocatalytic performance, since excellent electronic contact between the two $\mathrm{TiO}_{2}$ phases is a prerequisite for successful electron-hole separation and thus high photocatalytic activity.

Furthermore, it was observed from the photocatalysis experiments that the MIL-125- $\mathrm{NH}_{2}$-derived $\mathrm{TiO}_{2}$ suspension retained its white color throughout the photocatalytic test, in contrast to $\mathrm{TiO}_{4} \mathrm{H}_{4-}$, MIL-167-derived $\mathrm{TiO}_{2}$ and P25, which obtained a blue hue (Inset at Figure 5a). The blue color is attributed to the presence of $\mathrm{Ti}^{\mathrm{III}}$ in the $\mathrm{TiO}_{2}$, indicative of inefficient electron transport from the $\mathrm{TiO}_{2} \mathrm{NPs}$ to the water molecules or protons. Nevertheless, in the case of the MIL-125- $\mathrm{NH}_{2}$-derived $\mathrm{TiO}_{2}$, there was no $\mathrm{Ti}^{\mathrm{III}}$ observed, indicating superior electron transport and water reduction.

To further study this, photoluminescence ( $\mathrm{PL}$ ) experiments were performed to follow the irradiative recombination of the photo-excited charge carriers in the different $\mathrm{TiO}_{2}$ samples and thus to gain further insights into the charge separation efficiency (Figure S21). In principle, the electron-hole recombination can occur through different pathways, including irradiative recombination through trap states, in addition to the irradiative band gap emission, which is less observed with $\mathrm{TiO}_{2}$, being an indirect band gap semiconductor. ${ }^{43}$ In order to facilitate the comparison, the irradiative recombination of photogenerated charge carriers was quantified by integrating the PL emission curves of the different $\mathrm{TiO}_{2}$ samples (Table S2). The PL emission followed the order: MIL-167-derived $\mathrm{TiO}_{2}>\mathrm{TiH}_{4} \mathrm{O}_{4}$-derived $\mathrm{TiO}_{2}>\mathrm{P} 25$ Degussa $>$ MIL-125- $\mathrm{NH}_{2}$-derived $\mathrm{TiO}_{2}$. The PL results exhibit a comparable trend with the photocatalytic results, as the MIL-125- $\mathrm{NH}_{2}$-derived $\mathrm{TiO}_{2}$, which photocatalytically outperformed the other $\mathrm{TiO}_{2}$ samples demonstrated the lowest PL emission, followed by the P25, which was the second best performing photocatalyst.

\section{CONCLUSIONS}


In summary, we report a synthetic method in which MIL-125- $\mathrm{NH}_{2}$ crystals were used as a precursor for the preparation of $\mathrm{TiO}_{2}$ NPs composed of pure or mixed rutile and anatase phases. The crystals of MIL-125-NH 2 act as a template for the synthesis of $\mathrm{TiO}_{2}$ and the templated mixed-phase $\mathrm{TiO}_{2}$ (with anatase to rutile composition of 66:34) produced a $\mathrm{H}_{2}$ rate of $1394 \mu \mathrm{mol} \mathrm{h} \mathrm{h}^{-1} \mathrm{~g}^{-1}$. The optimum MIL-125- $\mathrm{NH}_{2}$-derived $\mathrm{TiO}_{2}$ notably outperformed the commercial P25 Degussa, the conventionally synthesized $\mathrm{TiH}_{4} \mathrm{O}_{4}$ - and MIL-167-derived $\mathrm{TiO}_{2}$. Two major aspects explain the high photocatalytic activity of the MIL-125- $\mathrm{NH}_{2}$-derived $\mathrm{TiO}_{2}: i$. the unique morphology that facilitates the constrained contact of NPs between the $\mathrm{TiO}_{2}$ anatase and rutile phases and ii. the distribution of the $\mathrm{TiO}_{2}$ anatase and rutile phases within the MIL-125- $\mathrm{NH}_{2}$-derived template. These combine to result in an enhanced synergistic effect, which significantly suppresses the undesired electron-hole recombination. Our study highlights that high charge separation efficiency can be morphologically-induced within $\mathrm{TiO}_{2}$ by using crystalline starting materials.

\section{ASSOSIATED CONTENT}

\section{Supporting Information}

The Supporting Information is available free of charge on the ACS Publication website at DOI: xx.

Experimental methods, materials, synthetic procedures, PXRD, TGA, Elemental analyses, SEM and TEM images, XPS, $\mathrm{N}_{2}$ isotherms and photocatalytic experiments are shown in the Supporting Information.

\section{AUTHOR INFORMATION}

\section{Corresponding Author}

* Email: kyriakos.stylianou@epfl.ch

Notes

$\dagger$ Denotes equal contribution to authorship

The authors declare no competing financial interest.

\section{ACKNOWLEDGEMENTS}

SK and KCS thank the Swiss National Science Foundation (SNF) for funding under the Ambizione Energy Grant no. PZENP2_166888. CPI is grateful to the EU for a Marie Curie Fellowship (705861 - ASPAir, H2020MSCA-IF-2015). The authors thank Mr. V.I.E. Queloz with assistance with the PL experiments, Dr. T. N. Nguyen for the synthesis of the MIL-167 and Profs. M. K. Nazeeruddin and R. Buonsanti for accessing their groups' infrastructure.

\section{REFERENCES}

(1) Zou, X.; Zhang, Y. Noble Metal-free Hydrogen Evolution Catalysts for Water Splitting. Chem. Soc. Rev. 2015, 44, 5148-5180.

(2) Schrauzer, G. N.; Guth, T. D. Photocatalytic Reactions. 1. Photolysis of Water and Photoreduction of Nitrogen on Titanium Dioxide. J. Am. Chem. Soc. 1977, 99, 7189-7193.

(3) Schrauzer, G. N.; Guth, T. D. Photolysis of Water and Photoreduction of Nitrogen on TitaniumDioxide. J. Am. Chem. Soc. 1977, 99, 7189-7193. 
(4) Fujishima, A.; Honda, K. Electrochemical Photolysis of Water at a Semiconductor Electrode. Nature 1972, 238, 37.

(5) Dahl, M.; Liu, Y.; Yin, Y. Composite Titanium Dioxide Nanomaterials. Chem. Rev. 2014, 114, $9853-$ 9889.

(6) Shi, L.; Li, Z.; Dao, T. D.; Nagao, T.; Yang, Y. A Synergistic Interaction between Isolated Au Nanoparticles and Oxygen Vacancies in an Amorphous Black TiO2 Nanoporous Film: toward Enhanced Photoelectrochemical Water Splitting. J. Mater. Chem. A 2018, 6, 12978-12984.

(7) Li, Z.; Shi, L.; Franklin, D.; Koul, S.; Kushima, A.; Yang, Y. Drastic Enhancement of Photoelectrochemical Water Splitting Performance over Plasmonic Al@TiO2 Heterostructured Nanocavity Arrays. Nano Energy 2018, 51, 400-407.

(8) Schneider, J.; Matsuoka, M.; Takeuchi, M.; Zhang, J.; Horiuchi, Y.; Anpo, M.; Bahnemann, D. W. Understanding $\mathrm{TiO}_{2}$ Photocatalysis: Mechanisms and Materials. Chem. Rev. 2014, 114, 9919-9986.

(9) Carp, O.; Huisman, C. L.; Reller, A. Photoinduced Reactivity of Titanium Dioxide. Prog. Solid State Chem. 2004, 32, 33-177.

(10) Bickley, R. I.; Gonzalez-Carreno, T.; Lees, J. S.; Palmisano, L.; Tilley, R. J. D. A Structural Investigation of Titanium Dioxide Photocatalysts. J. Solid State Chem. 1991, 92, 178-190.

(11) Kho, Y. K.; Iwase, A.; Teoh, W. Y.; Mädler, L.; Kudo, A.; Amal, R. Photocatalytic $\mathrm{H}_{2}$ Evolution over $\mathrm{TiO}_{2}$ Nanoparticles. The Synergistic Effect of Anatase and Rutile. J. Phys. Chem. C 2010, 114, $2821-$ 2829.

(12) Li, G.; Richter, C. P.; Milot, R. L.; Cai, L.; Schmuttenmaer, C. A.; Crabtree, R. H.; Brudvig, G. W.; Batista, V. S. Synergistic Effect between Anatase and Rutile $\mathrm{TiO}_{2}$ Nanoparticles in Dye-Sensitized Solar Cells. Dalton Trans. 2009, 10078-10085.

(13) Ohtani, B.; Prieto-Mahaney, O. O.; Li, D.; Abe, R. What is Degussa (Evonik) P25? Crystalline Composition Analysis, Reconstruction from Isolated Pure Particles and Photocatalytic Activity Test. J. Photochem. Photobiol. A 2010, 216, 179-182.

(14) Nosaka, Y.; Nosaka, A. Y. Reconsideration of Intrinsic Band Alignments within Anatase and Rutile $\mathrm{TiO}_{2}$. J. Phys. Chem. Lett. 2016, 7, 431-434.

(15) Scanlon, D. O.; Dunnill, C. W.; Buckeridge, J.; Shevlin, S. A.; Logsdail, A. J.; Woodley, S. M.; Catlow, C. R. A.; Powell, M. J.; Palgrave, R. G.; Parkin, I. P.; Watson, G. W.; Keal, T. W.; Sherwood, P.; Walsh, A.; Sokol, A. A. Band alignment of Rutile and Anatase TiO 2. Nat. Mater. 2013, 12, 798.

(16) Su, R.; Bechstein, R.; Sø, L.; Vang, R. T.; Sillassen, M.; Esbjörnsson, B.; Palmqvist, A.; Besenbacher, F. How the Anatase-to-Rutile Ratio Influences the Photoreactivity of $\mathrm{TiO}_{2}$. J. Phys. Chem. C 2011, 115, 24287-24292.

(17) Sun, B.; Smirniotis, P. G. Interaction of Anatase and Rutile $\mathrm{TiO}_{2}$ Particles in Aqueous Photooxidation. Catal. Today 2003, 88, 49-59.

(18) Malekshahi Byranvand, M.; Nemati Kharat, A.; Fatholahi, L.; Malekshahi Beiranvand, Z. A Review on Synthesis of Nano-TiO ${ }_{2}$ via Different Methods. J. Nanostruct. 2013, 3, 1-9.

(19) Valizadeh, B.; Nguyen, T. N.; Stylianou, K. C. Shape Engineering of Metal-Organic Frameworks. Polyhedron 2018, 145, 1-15.

(20) Bin, L.; Hui-Min, W.; Yuanjing, C.; Wei, Z.; Guodong, Q.; Banglin, C. Emerging Multifunctional Metal-Organic Framework Materials. Adv. Mater. 2016, 28, 8819-8860.

(21) Li, L.; Li, X.; Ai, L.; Jiang, J. MOF-Derived Nanostructured Cobalt Phosphide Assemblies for Efficient Hydrogen Evolution Reaction. RSC Adv. 2015, 5, 90265-90271.

(22) Jagadeesh, R. V.; Murugesan, K.; Alshammari, A. S.; Neumann, H.; Pohl, M.-M.; Radnik, J.; Beller, M. MOF-Derived Cobalt Nanoparticles Catalyze a General Synthesis of Amines. Science 2017, 358, 326-332.

(23) Rui, W.; Xi-Yan, D.; Jiao, D.; Jin-Yan, Z.; Shuang-Quan, Z. MOF-Derived Bifunctional $\mathrm{Cu}_{3} \mathrm{P}$ Nanoparticles Coated by a N,P-Codoped Carbon Shell for Hydrogen Evolution and Oxygen Reduction. Adv. Mater. 2018, 30, 1703711.

(24) Kumar, D. P.; Choi, J.; Hong, S.; Reddy, D. A.; Lee, S.; Kim, T. K. Rational Synthesis of MetalOrganic Framework-Derived Noble Metal-Free Nickel Phosphide Nanoparticles as a Highly Efficient Cocatalyst for Photocatalytic Hydrogen Evolution. ACS Sustain. Chem. Eng. 2016, 4, 7158-7166. 
(25) Tian, T.; Ai, L.; Jiang, J. Metal-Organic Framework-derived Nickel Phosphides as Efficient Electrocatalysts toward Sustainable Hydrogen Generation from Water Splitting. RSC Adv. 2015, 5, 10290-10295.

(26) Xiu, Z.; Alfaruqi, M. H.; Gim, J.; Song, J.; Kim, S.; Thi, T. V.; Duong, P. T.; Baboo, J. P.; Mathew, V.; Kim, J. Hierarchical Porous Anatase $\mathrm{TiO}_{2}$ Derived from a Titanium Metal-Organic Framework as a Superior Anode Material for Lithium Ion Batteries. Chem. Commun. 2015, 51, 12274-12277.

(27) Oar-Arteta, L.; Wezendonk, T.; Sun, X.; Kapteijn, F.; Gascon, J. Metal Organic Frameworks as Precursors for the Manufacture of Advanced Catalytic Materials. Mater. Chem. Front. 2017, 1, 17091745.

(28) Zhao, S.-N.; Song, X.-Z.; Song, S.-Y.; Zhang, H.-j. Highly Efficient Heterogeneous Catalytic Materials Derived from Metal-Organic Framework Supports/Precursors. Coord. Chem. Rev. 2017, 337, 80-96.

(29) Bhadra, B. N.; Song, J. Y.; Khan, N. A.; Jhung, S. H. TiO 2 -Containing Carbon Derived from a MetalOrganic Framework Composite: A Highly Active Catalyst for Oxidative Desulfurization. ACS Appl. Mater. Interfaces 2017, 9, 31192-31202.

(30) Dan-Hardi, M.; Serre, C.; Frot, T.; Rozes, L.; Maurin, G.; Sanchez, C.; Férey, G. A New Photoactive Crystalline Highly Porous Titanium(IV) Dicarboxylate. J. Am. Chem. Soc. 2009, 131, 10857-10859.

(31) Hu, S.; Liu, M.; Li, K.; Zuo, Y.; Zhang, A.; Song, C.; Zhang, G.; Guo, X. Solvothermal Synthesis of $\mathrm{NH}_{2}$-MIL-125(Ti) from Circular Plate to Octahedron. Cryst. Eng. Comm. 2014, 16, 9645-9650.

(32) Nguyen, T. N.; Kampouri, S.; Valizadeh, B.; Luo, W.; Ongari, D.; Planes, O. M.; Züttel, A.; Smit, B.; Stylianou, K. C. Photocatalytic Hydrogen Generation from a Visible-Light-Responsive Metal-Organic Framework System: Stability versus Activity of Molybdenum Sulfide Cocatalysts. ACS Appl. Mater. Interfaces 2018, 10, 30035-30039.

(33) Khaletskaya, K.; Pougin, A.; Medishetty, R.; Rösler, C.; Wiktor, C.; Strunk, J.; Fischer, R. A. Fabrication of Gold/Titania Photocatalyst for $\mathrm{CO}_{2}$ Reduction Based on Pyrolytic Conversion of the Metal-Organic Framework $\mathrm{NH}_{2}-\mathrm{MIL}-125$ (Ti) Loaded with Gold Nanoparticles. Chem. Mater. 2015, 27, 7248-7257.

(34) Yan, B.; Zhang, L.; Tang, Z.; Al-Mamun, M.; Zhao, H.; Su, X. Palladium-Decorated Hierarchical Titania Constructed from the Metal-Organic Frameworks $\mathrm{NH}_{2}-\mathrm{MIL}-125(\mathrm{Ti})$ as a Robust Photocatalyst for Hydrogen Evolution. Appl. Catal., B 2017, 218, 743-750.

(35) Kampouri, S.; Nguyen, T. N.; Ireland, C. P.; Valizadeh, B.; Ebrahim, F. M.; Capano, G.; Ongari, D.; Mace, A.; Guijarro, N.; Sivula, K.; Sienkiewicz, A.; Forro, L.; Smit, B.; Stylianou, K. C. Photocatalytic Hydrogen Generation from a Visible-Light Responsive Metal-Organic Framework System: The Impact of Nickel Phosphide Nanoparticles. J. Mater. Chem. A 2018, 6, 2476-2481.

(36) Hanaor, D. A. H.; Sorrell, C. C. Review of the Anatase to Rutile Phase Transformation. J. Mater. Sci. 2011, 46, 855-874.

(37) Particle Size Effects on Transformation Kinetics and Phase Stability in Nanocrystalline $\mathrm{TiO}_{2}$. Am. Mineral. 1997, 82, 717-728.

(38) Zhang, Z.; Brown, S.; Goodall, J. B. M.; Weng, X.; Thompson, K.; Gong, K.; Kellici, S.; Clark, R. J. H.; Evans, J. R. G.; Darr, J. A. Direct Continuous Hydrothermal Synthesis of High Surface Area Nanosized Titania. J. Alloys Compd. 2009, 476, 451-456.

(39) Kapilashrami, M.; Zhang, Y.; Liu, Y.-S.; Hagfeldt, A.; Guo, J. Probing the Optical Property and Electronic Structure of $\mathrm{TiO}_{2}$ Nanomaterials for Renewable Energy Applications. Chem. Rev. 2014, 114, 9662-9707.

(40) Ohno, T.; Sarukawa, K.; Tokieda, K.; Matsumura, M. Morphology of a $\mathrm{TiO}_{2}$ Photocatalyst (Degussa, P-25) Consisting of Anatase and Rutile Crystalline Phases. J. Catal. 2001, 203, 82-86.

(41) Assi, H.; Pardo Pérez, L. C.; Mouchaham, G.; Ragon, F.; Nasalevich, M.; Guillou, N.; Martineau, C.; Chevreau, H.; Kapteijn, F.; Gascon, J.; Fertey, P.; Elkaim, E.; Serre, C.; Devic, T. Investigating the Case of Titanium(IV) Carboxyphenolate Photoactive Coordination Polymers. Inorg. Chem. 2016, 55, 71927199.

(42) Qureshi, M.; Takanabe, K. Insights on Measuring and Reporting Heterogeneous Photocatalysis: Efficiency Definitions and Setup Examples. Chem. Mater. 2017, 29, 158-167. 
(43) Emeline, A. V.; Ryabchuk, V. K.; Serpone, N. Dogmas and Misconceptions in Heterogeneous Photocatalysis. Some Enlightened Reflections. J. Phys. Chem. B 2005, 109, 18515-18521.

TOC:

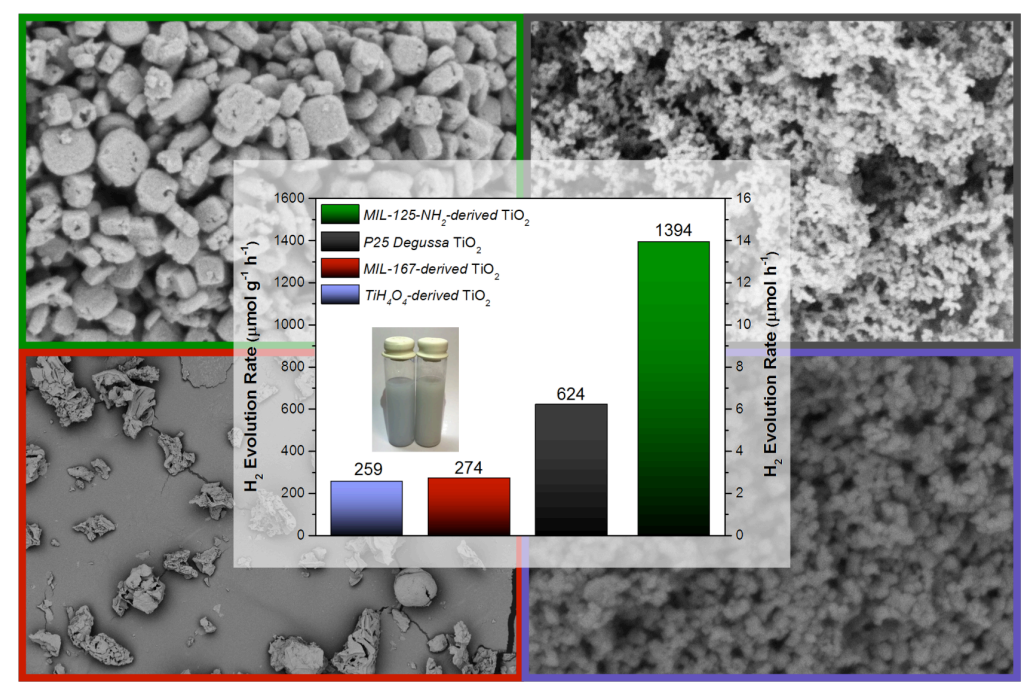

